\title{
Comparison of Modulation Formats for Use in the Next Generation Passive Optical Networks
}

\author{
Inna Kurbatska, Anita Alsevska, Lilita Gegere, and Vjaceslavs Bobrovs \\ Institute of Telecommunications, Riga Technical University, Riga, Latvia
}

\begin{abstract}
In this paper we are investigating the performance of different optical modulation formats in WDM-PON transmission system. On-off keying non-return-to-zero (NRZ-OOK), NRZ differential phase shift keying (NRZ DPSK), return-to-zero DPSK (RZ-DPSK, carrier-suppressed RZ DPSK (CSRZ-DPSK) and duobinary (DB) are reviewed.

The diversity of different broadband services offered to internet users today, causes growing of individual user demands to internet traffic. To satisfy these demands, capability of access network has to be increased. That is why the problem of increasing data capacity of access networks is actual for implementers of data transmission networks. Since WDM-PON is one of new and promising solutions for access networks, we are investigating it in this research. In its turn, the choice of right modulation format is one of the ways to increase a capacity of transmission network.

We use maximal achievable reach demonstrated by each optical modulation format for performance evaluation. To determine maximal reach, we investigate the longest distance, which allows providing data transmission with bit error rate (BER) less than $10^{-9}$ for each modulation format.

Our simulated WDM-PON system is 64 channel transmission system with $40 \mathrm{~Gb} / \mathrm{s}$ speed, that corresponds to the requirements for next generation PON2 (NG-PON2). Our transmission system is based on arrayed waveguide grating (AWG) multiplexers and demultiplexers. We use dispersion compensating fiber (DCF) to improve signal quality. The simulations are implemented using OptSim 5.2 software.

As a result, we figure out the modulation formats, which are able to provide maximal transmission distance in such way of WDM-PON system. In addition, we are comparing modulation formats in terms of BER simulating transmission over $40 \mathrm{~km}$ fiber span, according to NG-PON2 requirements.
\end{abstract}

\section{INTRODUCTION}

The diversity of different broadband services offered to internet users today, causes growing of individual user demands to internet traffic. Broadband applications, such as TV telephony, IP-TV, video conferencing, video on demand, interactive games and others, increases demands of internet users for internet traffic increase [1,2]. According to the Cisco visual network index forecast, metro traffic will account for 66 percent of total IP traffic by 2019 [3]. That is why service providers are re-evaluating their access networks strategy and try to find new solution, which will be able to meet demand of capacity and user density requirements, while ensuring that the cost per unit bandwidth is lowest possible [2]. Perspective solution widely applied today is the introduction of a broadband access network based on fiber-to-the-office (FTTO) and fiber-to-the-home (FTTH)[1]. In its turn, the most cost-effective way to deploy FTTH networks is passive optical networks (PON) technology.

PONs ensure higher reliability, simpler maintenance and reduced power consumption in comparison with active optical networks (AONs) [4]. According to [5] Gigabit-Capable PON (GPON) is currently dominating in the world market, but 10 gigabit Ethernet-PON (10G-EPON) and 10GPON (XG-PON) are currently in beginning phase of mass-market adaptation [4]. However, need to improve performance and decrease costs drives new standards. The next-generation PON (NGPON) with much higher bandwidth will feasibly be able to satisfy these demands. NG-PON1 considers the ODN to remain unchanged, whereas NG-PON2 means revolutionary change of ODN. XG-PON has already been selected as the best candidate for NG-PON1 solutions, but one of proposed candidates for NG-PON2 is WDM-PON. Requirements to NG-PON2 includes at least $40 \mathrm{~Gb} / \mathrm{s}$ aggregate downstream capacity, more than 64 channels and $40 \mathrm{~km}$ differential reach $[4,6]$. That is why our WDM-PON system simulates transmission of 64 channels with $40 \mathrm{~Gb} / \mathrm{s}$ speed.

The right choice of modulation format can significantly influence system performance by increasing system reach and capacity. Different types of modulation formats have different resistance 
to chromatic dispersion (CD), polarization-mode dispersion (PMD) and non-linear optical effect$\mathrm{s}$ (NOE). Among four basic modulation types, two of them - amplitude modulation (AM) also known as on-of keying (OOK) and phase modulation (PM) - are widely used in fiber optics systems [7]. Advanced modulation formats, such as quadrature-amplitude modulation (QAM), quadraturephase-shift keying (QPSK), can effectively overcome problems with CD, PMD and NOE [7]. However, in this paper, we investigate if simple modulation formats (NRZ-DPSK, RZ-DPSK, CSRZ-DPSK and DB), which are easier to implement, can meet abovementioned requirements.

According to [7] RZ-DPSK and CSRZ-DPSK show better power penalty than NRZ-DPSK and NRZ-OOK at $40 \mathrm{Gbit} / \mathrm{s}$ speed. However, RZ-DPSK and CSRZ-DPSK achieve the same bit error rate (BER) with smaller receiver sensitivity [7]. Authors in [8] present that in 16 channel 40 Gbit/s TDMA-PON NRZ-OOK show slightly longer reach with the same BER than NRZ-DPSK. On the contrary, in [9] after transmission with $40 \mathrm{Gbit} / \mathrm{s}$ over $12 \mathrm{~km}$ standard single mode fiber (SSMF) RZ-DPSK and NRZ-DPSK demonstrated higher value of Q-factor than NRZ-OOK, but DB showed significantly better result. Different performance of modulation formats, as DPSK in above considered studies, confirms the necessity to evaluate performance of modulation format for specific type of system. In this paper, we investigate if DB, NRZ-DPSK and RZ-DPSK are able to demonstrate the better performance in comparison with NRZ-OOK traditionally used in PON. We evaluate the performance of modulation formats for the 64 channel $40 \mathrm{Gbit} / \mathrm{s}$ WDM-PON with dispersion compensation using dispersion-compensating fiber (DCF).

\section{SIMULATION MODEL}

We used OptSim software for our simulations. It simulates signal propagation in optical fiber using the Time Domain Split Step (TDSS) technique for solving the nonlinear Schrödinger equation. Dividing fiber to small spans according to TDSS method allows simulating linear and nonlinear effects independently from each over [10].

We simulated the downstream transmission of 64 channels with $40 \mathrm{Gbit} / \mathrm{s}$ speed and $100 \mathrm{GHz}$ channel spacing. We chose frequencies of channels according to WDM frequency grid (ITU-T G.694.1) with $193.1 \mathrm{GHz}$ central frequency [11].

As one can see at Fig. 1, our simulation scheme consists from optical line terminals (OLTs), optical distribution network (ODN) and optical network terminals (ONT).

OLTs are situated at central office (CO) of provider. In our simulation scheme, OLT is responsible for signal transmission to user. That is why it consists from optical transmitter.

ODN includes transmission line (ITU-T G.652 single mode fiber (SMF)), arrayed waveguide grating (AWG) multiplexer and demultiplexer and dispersion compensating fiber (DCF). To simulate insertion loss of multiplexer and demultiplexer $-3 \mathrm{~dB}$ attenuators are used[12] AWG multiplexer is situated at $\mathrm{CO}$, but demultiplexer at remote terminal (RT). Besides combining and splitting, AWG multiplexer and demultiplexer performs optical filtering by Gaussian filters (GF).

ONTs are situated at premises of users. In our case the function of ONT is signal reception and consists from receiver and electrical Bessel filter (BF) Receiver is PIN photodiode in OOK case, see Fig. 1(a). DPSK receiver is shown at Fig. 1(b). It consists from Mach-Zehnder interferometer,

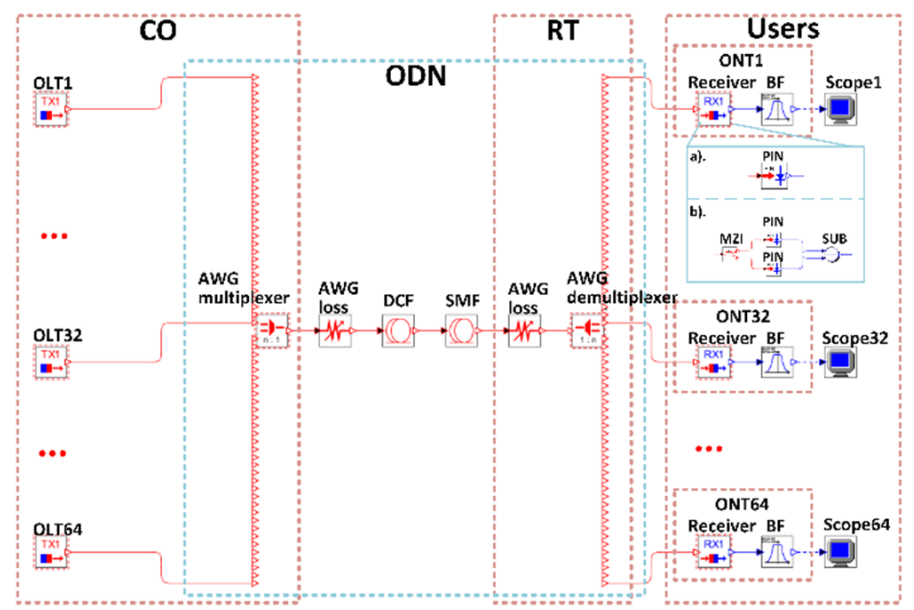

Figure 1: Simulation scheme of 16-channel WDM-PON transmission system with $40 \mathrm{Gbit} / \mathrm{s}$ transmission speed per channel. (a) OOK receiver, (b) DPSK receiver. 

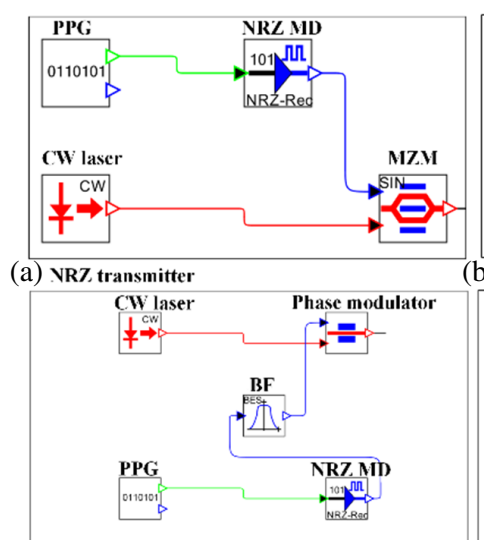

(d) NRZ-DPSK transmitter

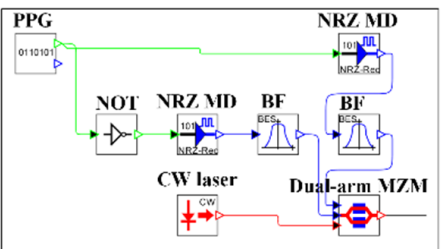

(b) DB transmitter

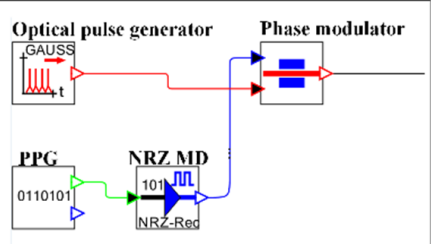

(e) RZ-DPSK transmitter

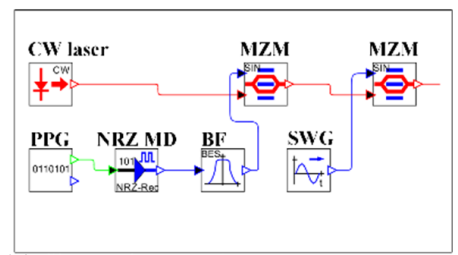

(c) CSRZ-DPSK transmitter

Figure 2: Different type optical transmitters for realization of following modulation formats: (a) NRZ, (b) DB, (c) CSRZ-DPSK, (d) NRZ-DPSK, and (e) RZ-DPSK.

two PIN photodiodes and substractor (SUB). Photodiodes are the same for both receiver types.

The schemes of transmitters for realization of studied modulation formats is shown at Fig. 2 . Fig. 2(a). shows NRZ transmitter, which is based on the Mach-Zehnder modulator (MZM). Pulse pattern generator (PPG) generates pseudo-random bit sequence at $40 \mathrm{Gbit} / \mathrm{s}$. NRZ modulator driver (MD) uses this sequence to form NRZ electrical signal. MZM modulates optical signal from continuous wave $(\mathrm{CW})$ laser using the electrical signal from MD. In DB transmitter, shown at Fig. 2(b), two inverse pre-filtered NRZ signals drives dual-arm MZM. Two MZMs forms CSRZDPSK transmitter at Fig. 3(c). The first MZM is driven by filtered NRZ signal, the second using signal from sinusoidal wave generator (SWG) with amplitude equal to MZM driving voltage and frequency equal to half data rate. As one can see at Fig. 2(d) and Fig. 2(e) NRZ-DPSK and RZ-DPSK transmitters have similar structure. They both are based on phase modulator. The main difference is that optical Gaussian pulse generator is used as an optical signal source. In addition, in NRZ-DPSK transmitter driving electrical signal is pre-filtered.

The key parameters of elements are summarized in Table 1.

Table 1: The key parameters of WDM-PON elements.

\begin{tabular}{|c|c|c|}
\hline Element & Parameter & Value \\
\hline \multirow{3}{*}{ DCF } & attenuation coefficient & $0.6 \mathrm{~dB} / \mathrm{km}$ \\
\cline { 2 - 3 } & dispersion coefficient & $-80 \mathrm{ps} /(\mathrm{nm} \cdot \mathrm{km})$ \\
\cline { 2 - 3 } & dispersion slope & $0.19 \mathrm{ps} /\left(\mathrm{nm}^{2} \cdot \mathrm{km}\right)$ \\
\hline \multirow{2}{*}{ PIN photodiode } & responsivity & $0.8 \mathrm{~A} / \mathrm{W} @ 1550 \mathrm{~nm}$ \\
\cline { 2 - 3 } & dark current & $10 \mathrm{nA}$ \\
\hline MZM & extinction ratio & $20 \mathrm{~dB}$ \\
\hline \multirow{2}{*}{ Optical source } & output power & $2 \mathrm{dBm}$ \\
\cline { 2 - 3 } & linewidth & $50 \mathrm{MHz}$ \\
\hline
\end{tabular}

\section{RESULTS AND DISCUSSION}

Evaluating the maximal transmission link distance achievable by each format, we observed that that BER of different channels for all formats accept DB differs significantly. The maximal reach was determined assuming that transmission is successful with BER less than $10^{-9}$ for each channel.

DB demonstrated the best result, achieving $70 \mathrm{~km}$ long maximal reach, see Table 2 . This is the only format, which was able to ensure transmission over the distance longer than $40 \mathrm{~km}$. The performance of DPSK formats is only slightly better than performance of traditional NRZ-OOK.

During the simulations, we observed that the values of optical filter bandwidth influences the maximal reach significantly. Our found the most successful combinations of optical and electrical filters bandwidths combinations are summarized in Table 3. 
Table 2: Maximal transmission distance of studied modulation formats.

\begin{tabular}{|c|c|}
\hline Format & Distance $(\mathrm{km})$ \\
\hline DB & 70 \\
\hline RZ-DPSK & 35 \\
\hline CSRZ-DPSK & 30 \\
\hline NRZ-DPSK & 30 \\
\hline NRZ-OOK & 25 \\
\hline
\end{tabular}

Table 3: Optical and electrical filter bandwidths for studied modulation formats.

\begin{tabular}{|c|c|c|}
\hline Format & GF bandwidth $(\mathrm{GHz})$ & BF bandwidth $(\mathrm{GHz})$ \\
\hline DB & 58 & 22 \\
\hline RZ-DPSK & 40 & 55 \\
\hline CSRZ-DPSK & 50 & 35 \\
\hline NRZ-DPSK & 70 & 65 \\
\hline NRZ-OOK & 70 & 60 \\
\hline
\end{tabular}

We also evaluated BER for each modulation format after transmission over $40 \mathrm{~km}$ long distance. As BER differs for different channels, Fig. 3 illustrates BER values for each channel. We limited $y$-axis up to 12 , which corresponds to BER of $10^{-12}$, because it is impossible to measure smaller BER values in practice [9].

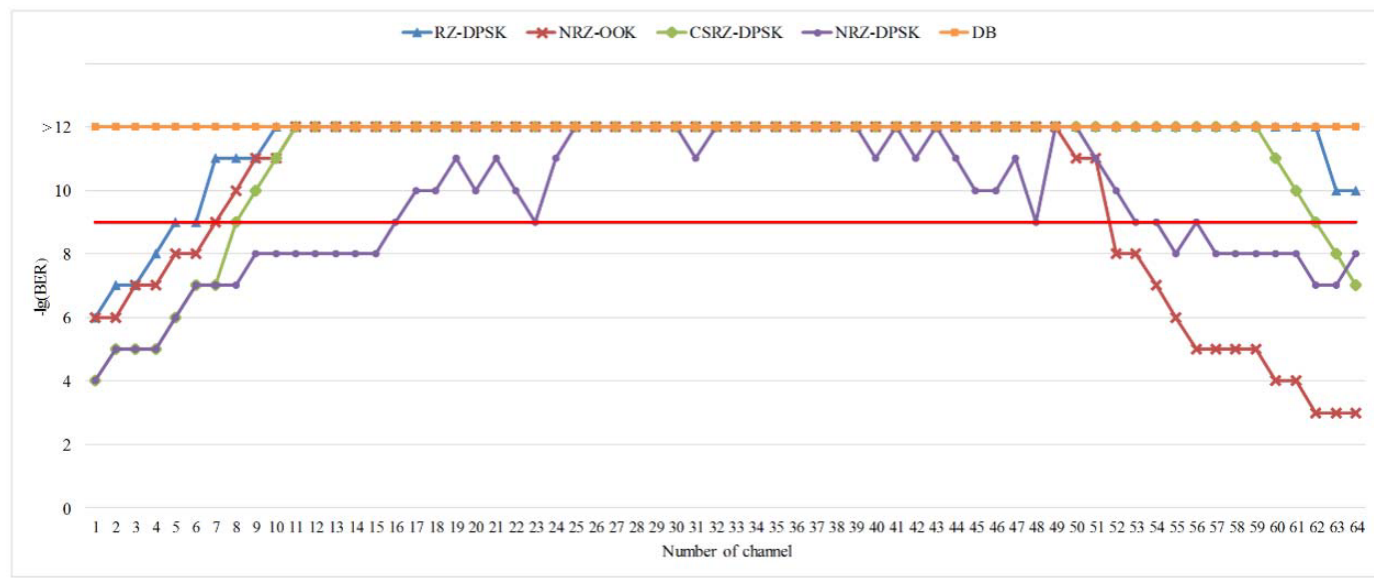

Figure 3: $40 \mathrm{~Gb} / \mathrm{s}$ transmission DB, RZ-DPSK, CSRZ-DPSK, NRZ-DPSK and NRZ-OOK over $40 \mathrm{~km}$ long distance. BER performance of each of 64 channels.

Only using DB modulation, after transmission over $40 \mathrm{~km}$ fiber span all channels obtain BER smaller than $10^{-9}$. All modulation formats, except DB, show significant difference between BER of channels. NRZ-OOK format have the most uneven results. Nevertheless, the distribution of BER is not random - external channels have the highest BER values. This means that NOE influence other formats more critically than DB. Authors in [9] present similar results — DB yields better performance in comparison with NRZ-OOK and DPSK formats, but DPSK formats are slightly better than NRZ-OOK. However, differences in BER values between showed nine channels are small for all formats.

To figure out which of modulation formats is most effected by NOE, we summarized number of channels with BER higher than $10^{-9}$. For NRZ formats (both DPSK and OOK) channel number with high BER values is 19 and 24 respectively, that is significantly bigger than for RZ-DPSK and CSRZ-DPSK (4 and 9 channels respectively).

\section{CONCLUSIONS}

DB demonstrated significantly better performance than other investigated modulation formats. DB is able to achieve $70 \mathrm{~km}$ reach with BER less than $10^{-9}$ in comparison with $25-35 \mathrm{~km}$ achieved by 
other formats. This means that DB is considerable for using in NGPON2 as it is able to meet distance, speed and channel number requirements. This format is able to show much better results in $40 \mathrm{Gbit} / \mathrm{s}$ WDM-PONs.

Simulation of transmission over $40 \mathrm{~km}$ long SMF demonstrated that only DB shows the small difference in BER values of different channels. It is the only format from studied using which BER of all channels does not exceed $10^{-9}$ threshold. However, RZ-DPSK and CSRZ-DPSK have relatively small number of channels with higher BER. For RZ-DPSK this number is four channels, for CSRZ-DPSK-9 channels in comparison with 24 and 19 channels of NRZ OOK and DPSK. This allows concluding that, it can be worth to evaluate, whether the use of RZ-DPSK and CSRZ-DPSK can be more cost-effective or less-power consuming than the use of DB.

\section{ACKNOWLEDGMENT}

This research has been supported by the national research program in Latvia within the project Nr. 10-4/VPP-4/11.

\section{REFERENCES}

1. Iwatsuki, K., "Application and technical issues of WDM-PON," Broadband Access Communication Technologies IV, Proc. of SPIE, Vol. 7620, 76200C, 2010.

2. Ozolins, O., V. Bobrovs, and G. Ivanovs, "DWDM-direct access system based on the fiber Bragg grating technology," Proc. of the 2012 8th International Symposium on Communication Systems, Networks and Digital Signal Processing, 2012

3. Cisco inc, "Cisco visual networking index: Forecast and methodology, 2014-2019," White Paper, 2015.

4. Muciaccia, T., F. Gargano, and V. M. N. Passaro, "Review passive optical access networks: State of the art and future evolution," Photonics, No. 1, 2014.

5. Jansons, G., "What is GPON? - Short recap," 2015, http://www.edgetech.lv/what-is-gpon/.

6. Carroll, M., D. Nesset, and P. Dawes, "FSAN highlights \& NG-PON2 standards update," FSAN and IEEE NG-EPON/1904 ANWG Joint Session hosted by Cable Labs, February 4, 2015.

7. Binh, L. N., Advanced Digital Optical Comunications, 2nd Edition, CRC Press, Munich, 2015.

8. Maneekut, R., T. Sakchaichanchon, V. Ket-Urai, and P. Kaewplung, "Recent progress of the next generation 40-Gbps signal transmission over passive optical network using the advance modulation formats," Optical Communications and Networks (ICOCN), 11th International Conference on, Chonburi, 1-4, 2012.

9. Agalliu, R. and M. Lucki, "System improvements in dense wavelength division multiplexing networks by using advanced optical modulation formats," ICTION, 2015.

10. RSoft Design Group, Inc., OptSim User Guide, 459, RSoft Design Group, USA, 2010.

11. Spolitis, S., V. Bobrovs, and G. Ivanovs, "New generation energy efficient WDM-PON system using spectrum slicing technology," International Congress on Ultra Modern Telecommunications and Control Systems and Workshops, 2012.

12. Bobrovs, V., S. Spolitis, G. Ivanovs, and P. Gavars, "Performance improvementof high speed spectrum-sliced dense WDM-PON system," 9th International Symposium on Telecommunications, Bihtel, 2012.

This is a post-print of a paper published in Proceedings of the 2016 Progress in Electromagnetics Research Symposium (PIERS 2016 Shanghai) http://dx.doi.org/10.1109/PIERS.2016.7735425 and is subject to IEEE copyright. 